\title{
HYDATID CYST;
}

AT RARE SITES EXPERIENCE AT TERTIARY CARE HOSPITAL

Dr. Farzana Memon, Dr. Atif Sitwat, Dr. Jawaid Hussain Memon.

ABSTRACT.....Background: Ecchino coccosis or hydatid cyst disease is a common parasitic disease that is known to affect both humans and animals and is an important health problem in poorly developed countries. Objectives: In this histopathological retrospective study, we aimed to evaluate hydatid cyst disease occurring at different sites of body and were diagnosed during last fifteen years in pathology department, Liaquat University of Medical and Health Sciences (LUMHS), Jamshoro from January 1996 to December 2010. Study Design: Descriptive retrospective study. Materials: A total of 80 cases of hydatid cyst disease of different organs diagnosed at pathology department LUMHS Jamshoro and retrieved from Histopathological record. Results: Out of these 80 cases, 56 cases (70\%) were of liver, $8(10 \%)$ of lung, $5(6.25 \%)$ of ovary. 01 case $(1.2 \%)$ thyroid, 02 cases $(2.5 \%)$ submandibular region and 8 (10\%) each occurring at thigh, forearm, palm, cheek and fronto-temporal region. Majority of cases seen in females and M/F ratio of $1: 3.6$ and with age range of $8-65$ years. More than $50 \%$ of cases were seen between 30-65 years of age. Conclusion: Hydatid cyst of liver was most common site followed by lung. But it can also be included in differential diagnosis of solitary cystic lesions of ovary and thyroid as well.

Key words: Hydatid cyst, rare sites, ovary and thyroid, sites other than liver and lung.

Article Citation

Memon F, Sitwat A, Memon JH. Hydatid cyst; at rare site experience at tertiary care hospital. Professional Med J 2013;20(5): 772-775.

\section{INTRODUCTION}

Hydatid cyst disease is a Unique Parasitic disease that is endemic in many parts of the world ${ }^{1}$. Ecchinococcosis or hydatid cyst disease is a common parasitic disease that is known to affect both human and animals and is an important health problem in poorly developed countries.

Ecchinococcosis manifests as a cyst formation; is caused by $E$. Granulosis (unilocular cyst) and E. Alveolosis (multilocular cyst) ${ }^{2}$. Hydatid disease is endemic in middle east as well as other parts of the world including Asia, South America, New Zealand, Australia, Turkey and Southern Europe ${ }^{3-4}$.

Ecchinococcosis (hydatid disease) is common in developing countries and is classically confirmed by direct demonstration of broad capsules, Scolices and hooklets. Secondary development of the cysts in various organs other than primary sites often poses a diagnostic problem. In most of the reported cases, these structures have been identified in different clinical conditions and specimen. Occurrence of $60 \%$ of hydatid cyst in liver, 30\% in lungs, 2.5\% in kidney,
$2.5 \%$ in heart, less than $2.5 \%$ in bone, spleen, muscle and brain have been reported. Other rare sites are orbit, urinary bladder, chest wall, parotid thyroid and retroperitoneal tissue ${ }^{5}$.

Hydatid cyst is endemic in cattle and sheep raising regions of world and also commonly seen in most sheep raises areas of $\operatorname{Sindh}^{6}$.

In Pakistan hydatid cyst are quite frequently observed. In a large case report of 172 cases by Qamar Jamal and N.A. Jaffery ${ }^{6}$ reveals a wide range of its localization.

The most common sites are liver and lungs, other sites are brain, neck, bone, orbit, kidney and abdominal wall.

In our series we encountered 3 cases of ovarian hydatid cyst and one case of thyroid hydatid cyst.

Hydatid cyst should be included in different diagnosis of cystic lesions of ovary and thyroid as well. 


\section{MATERIALS AND METHODS}

This is an observational descriptive study carried out retrospectively.

A total of 80 cases of hydatid cyst disease of different organs were received in department of pathology LUMHS Jamshoror from Jan 1996 to Dec 2010, were included in this study. All details regarding Age, sex, occupation, residency and sites of location were evaluated from clinical and histopathological proforma.

\section{RESULTS}

Out of these 80 cases, 56 cases (70\%) were of liver, 8 cases (10\%) lung, 5 cases (6.25\%) ovary, each one of thyroid $(1.25 \%)$ submandibular region $(2.5 \%)$ and remaining 8 cases (10\%) were of soft tissue including thigh, forearm, palm, cheek and fronto-temporal region. Commonly females were affected more and with $\mathrm{M} / \mathrm{F}$ raio of 1:3.6, with age range of 8-65 years. More than $50 \%$ of cases are seen between $30-65$ years of age. Majority of females were house wives and also working in agricultural fields and males were farmers and labourers.

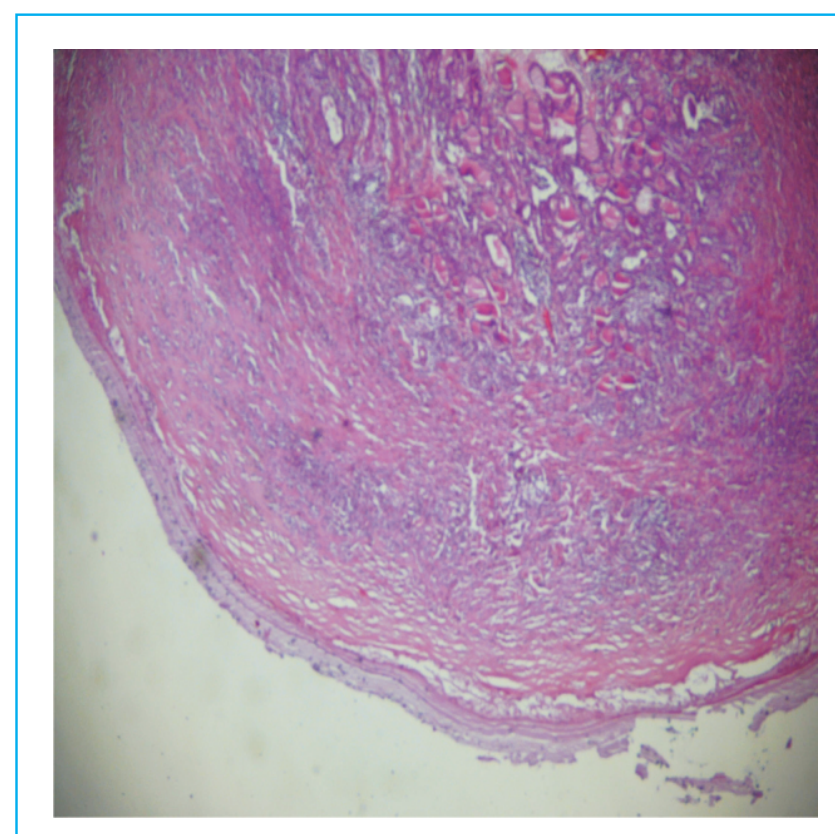

High power view of hydatid cyst of thyroid

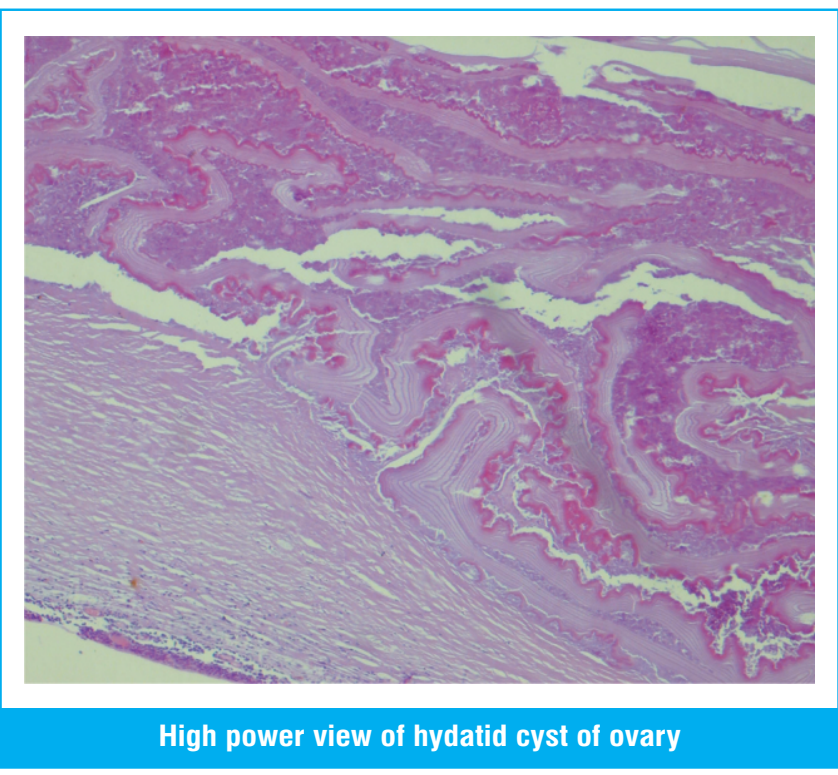

\begin{tabular}{|c|c|c|}
\hline Site & No. of cases & Percentage \\
\hline Liver & 56 & 70 \\
\hline Lung & 08 & 10 \\
\hline Ovary & 05 & 6.25 \\
\hline Thyroid & 01 & 1.25 \\
\hline Submandibular region & 02 & 2.5 \\
\hline Thigh & 02 & 2.5 \\
\hline Forearm & 02 & 2.5 \\
\hline Palm & 01 & 1.25 \\
\hline Cheek & 02 & 2.5 \\
\hline Fronto-temporal region & 01 & 1.25 \\
\hline Total & 80 & 100 \\
\hline
\end{tabular}

Table-I. Dififerent sites of hydatid eyst including rare site

\section{DISCUSSION}

Hydatid cyst disease is a parasitic infestation, which is endemic in many parts of the world. Hydatid disease has been eradicated in many countries, but it is still wide spread in communities in which agriculture dominates, thus cystic hydatidosis is a significant public health concern in regions where ecchinococcosis is endemic ${ }^{7}$.

In some endemic countries, females are affected more 
than male because of their living style bring them into contact with the parasite ${ }^{7}$. In our series females were affected more than males with $1: 3.6 \mathrm{M} / F$ ratio.

Hydatid cyst may be found in almost every part of the body, but most often in liver followed by lungs ${ }^{8}$. Our series also shows highest number of cases $(70 \%)$ in liver followed by lung (10\%).

Ovarian hydatid disease is rare and only few cases are reported in literature. Involvement of ovaries is generally secondary to peritoneal spread of daughter cyst due to rupture of a liver HC, but isolated primary ovarian involvement has been reported and may remain asymptomatic for long time and my be discovered incidentally or may cause compression symptoms $^{9}$. In our series 3 cases $(6 \%)$ of ovarian hydatid cyst were diagnosed. Two cases were diagnosed incidentally and in one case it presented as cystic ovarian mass and diagnosed on microscopic examination.

Few cases of hydatid cyst of thyroid are also reported in literature ${ }^{10,11,12}$. In our series one case $(2 \%)$ of hydatid disease was seen and initially refered for FNAC. It was performed using $23 \mathrm{G}$. needle and thick turbid creamy fluid was aspirated. Post FNAC period was uneventful. FNA smear were stained with Papanicolaou and H\&E stains. The smears show fragments of hyaline laminated cyst wall membrane in a background of cellular debris. The diagnosis of hydatid cyst was confirmed by presence of scolices and hooklets of echinococus on histopatholgy.

Soft tissue HD occurs in $2.3 \%$ of patients living in endemic areas ${ }^{13}$. The growth of cyst within a muscle is difficult because of its contractility and presence of lactic acid.

We are also reporting 8 cases (10\%) of soft tissue HD each occurring at thigh, forearm, palm, cheek and fronto-temporal region.

\section{CONCLUSION}

The purpose of our study is to emphasize the fact that this disease should be suspected in cystic lesion affecting any organ in the body especially in endemic areas and it should be included in differential diagnosis of cystic lesions of ovary and thyroid.

\section{Copyright@ 26 May, 2013.}

\section{REFERENCES}

1. Pinar Polat, Mecit Kantarci, Fatih Alper. Hydatid disease from head to toe. Radiographics, 2003; 23:475-494.

2. Nihal Kilinc, Cigdem Arican. A hydatid cyst found in an uncommon site coincidentally. Pak J Medi Sci. OctDec 2007 (Part-1) Vol.23, Nos 774-776.

3. Goel MC, Agarwal MR, Misra A. Percutaneous drainage of renal hydatid cyst, early results and follow up. Br J urol 1995; 75:724-8.

4. Brown RA, Millar AIW, Steiner Z, Krige JEJ, Burkimsher D. Cywes S. Hydatid cyst of the pancrease, a case report in a child. Eur J pediatr Surg 1995; 5:121-4.

5. Bijay R Mirdha and A. Biswas. Ecchinococcosis presently as palpable lump of breast. Indian $\mathrm{J}$ Chest disese Allied Sci 2001; 43:241.

6. Qamar Jaml. Jaffery NA. Hydatid cyst at Jinnah Post Graduate Medical Centre Karachi. JPMA; 1989; 39:320.

7. Brunetti E, Filice C. Echinococcosis hydatid cyst. Medicine 2006; 1-11.

8. Sahin E, Nayki U, Sadik S. Abdominal and Pelvic hydatid disease during pregnancy. Arch Gynecol Obstet 2005; $273: 58-9$.

9. Hang val $\mathrm{H}$, Habibi $\mathrm{H}$, Moshref $\mathrm{A}$, Rahimi A. Case report of an ovarian hydatid cyst. J Trop Med hyg 1979; 82 34-35.

10. Erkili S, Ozsara ASC, Koaser NE. Hydatid cyst of thyroid gland in a child. Int J Pediatr otorhinolaryngol 2004; 68(3):369.

11. Saha A, Paul UK, Kumar K. Diagnosis of primary hydatid cyst in thyroid by fine needle aspiration 
cytology. J Cytol 2007; 24: 137-139.

12. Jain SK, Jamdade PT, Muneshwar SS, Ambulgekar V K Hydatid cyst of thyroid. An unusual cause of stridor.
Indian J otolaryngol. Head Neck Surg 2005; 57:80-81.

13. Englin G, A cunas B, Rozanes I, Acunas G. HD with unusual localization. Eur Radiol 2000; 10:1904-1912.

\section{AUTHOR(S):}

1. DR. FARZANA MEMON

MBBS, M. Phil (Pathology)

Associate Professor Pathology

LUMHS, Jamshoro.

2. DR. ATIF SITWAT

MBBS, M.D (Medicine)

Assistant Professor Medicine

Isra University, Hyderabad.

3. DR. JAWAID HUSSAIN MEMON

MBBS, M. Phil (Pathology)

Assistant Professor Pathology

Peoples University of Medical \& Health Sciences,

(PUMHS) for Women,

Nawabshah (Shaheed Benazirabad)

\section{Correspondence Address:}

Dr. Farzana Memon

Associate Professor Pathology

LUMHS, Jamshoro.

drfarzana_memon@hotmail.com

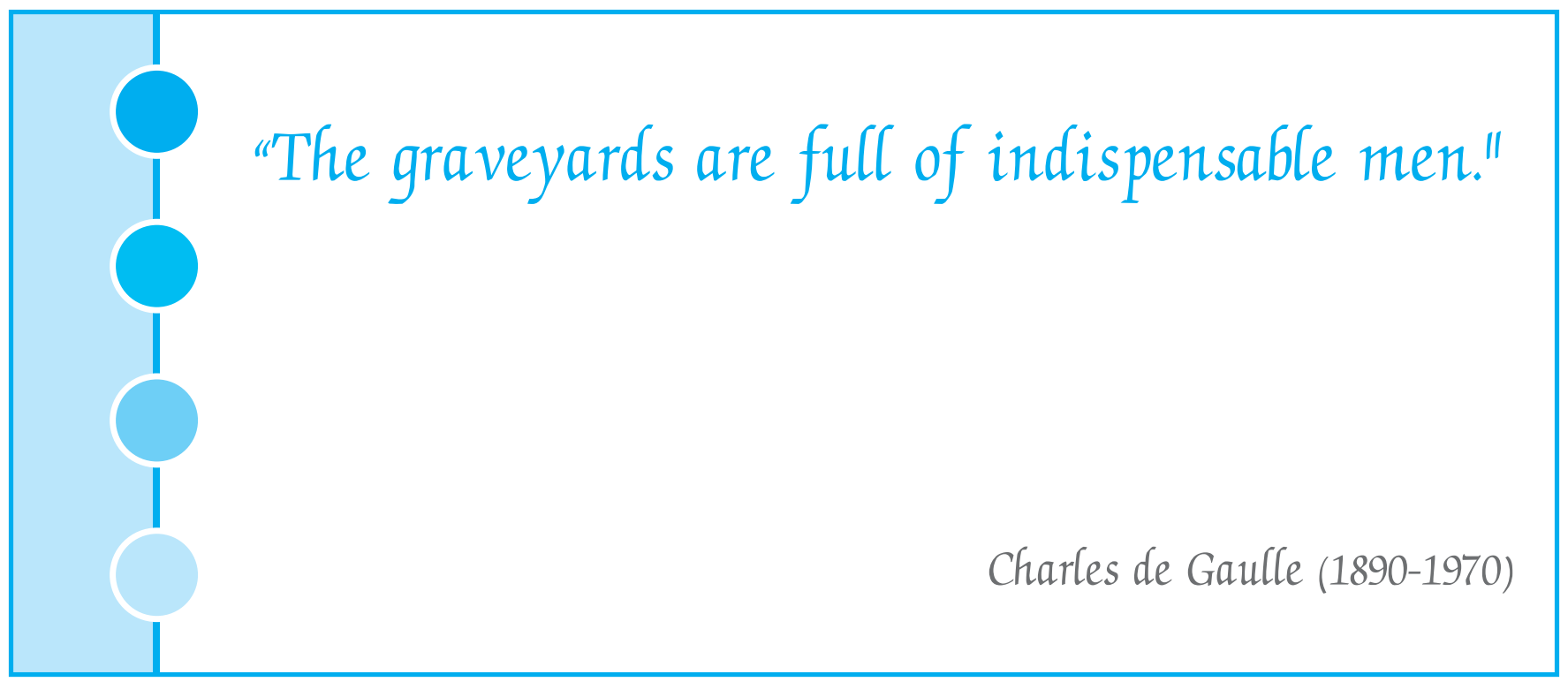

